\title{
UTILIZAÇÃO DO PICRO-SIRIUS PARA CORAR O PARACOCCIDIOIDES BRASILIENSIS
}

\author{
Hipólito de Oliveira Almeida, Marilda da Costa \\ Brandão, Maria das Graças Reis de Morais, Marlene Antonia \\ dos Reis e Suzana Aperecida Silveira
}

\begin{abstract}
A solução do picro-sirius foi usada para corar o Paracoccidioides brasiliensis em tecidos humanos fixados em formol. $\dot{A}$ luz comum, ofungo mostra uma faixa periférica avermelhada e, à luz polarizada, apresenta um ou mais anéis birrefringentes esverdeados. $A$ imersão prévia em solução de hidróxido de sódio a $1 \%$, por alguns minutos, melhora a coloração, sendo o fungo visualizado com mais nitidez à luz polarizada. Por outro lado, a diferenciação dos cortes corados, com picro-sirius em hidróxido de sódio a $0,5 \%$, elimina a birrefringência do colágeno mais rapidamente que $a$ do Paracoccidioides.
\end{abstract}

Palavras chaves: Paracoccidioides brasiliensis. Paracoccidioidomicose. Picrosirius. Histotecnologia. Micoses.

A coloração pelo picro-sirius é empregada em histologia como especifica para colágenos, aumentando a birrefringência deste material ${ }^{2346}$. Entretanto o Cryptococcus neoformans, quando tratado por esse corante, mostra aneis birrefringentes em seu envoltório' ${ }^{1}$. Como o Paracoccidioides é um fungo que tem algumas propriedades tintoriais semelhantes às do Cryptococcus, é provável que, quando corado com o picro-sirius, também se torne birrefringente. Tal possibilidade levou-nos a testar esta coloração em casos de Paracoccidioidomicose do nosso arquivo de necrópsias. No presente estudo, além da técnica clássica do picro-sirius, testamos algumas modificações visando simplificações e melhora da visualização do fungo.

\section{MATERIAL E MÉTODOS}

Foram utilizados fragmentos de linfonodos, pulmões, baço e figado, fixados e conservados em formol comercial a $10 \%$, por periodo que variou de 6 meses a 10 anos, provenientes de 5 casos de paracoccidioidomicose e de 2 casos-controles de tuberculose. $O$ diagnóstico de paracoccidioidomicose teve por base a identificação do fungo em coloraçōes pela hematoxilina-eosina, Grocott e PAS. Dos fragmentos, incluídos em parafina, foram obtidos cortes de 5 a 7 micrômetros que foram desparafinados, hidratados e colocados na solução corante (picro-sirius) por tempo que variou de $10,20,30,40,50$ ou 60 minutos. Alguns cortes, antes da coloração, foram banhados em solução de hidróxido de sódio a $1 \mathrm{~g} \%$ por $2,5,10,15$ ou 20 minutos, em seguida lavados em água destilada e imersos na

Trabalho realizado na Disciplina de Patologia Geral da Faculdade de Medicina do Triângulo Mineiro, Pça. Manoel Terra s/n:, 38100 Uberaba-MG.

Recebido para publicaçâo em $8 / 6 / 87$ solução corante; outros, após a coloração foram imersos em solução aquosa de hidróxido de sódio a $0,5 \mathrm{~g} \%$ com leve agitação para diferenciação rápida (menos de um minuto) até perder a cor vermelha, seguida de banho em água de torneira; um quarto grupo, de preparados histológicos, foi tratado com hidróxido de sódio antes e após a coloração. Após estes tratamentos, os cortes eram processados rotineiramente para montar em Entelan e examinados ao microscópio comum e de luz polarizada. Alguns cortes foram apenas desparafinados e montados, enquanto outros foram banhados em hidróxido de sódio, montados e examinados. A solução corante constou de água destilada à qual se adiciona ácido pícrico até à saturação $( \pm 1,2 \mathrm{~g} \%)$ e depois o vermelho da Síria (Sirius Red) F3B, na concentração de $0,1 \mathrm{~g} \%$.

\section{RESULTADOS}

Os cortes corados pelo picro-sirius, sem outro tratamento adicional, quando analisados ao microscópio de luz comum, mostram áreas intensamente coradas em vermelho (colágeno) e áreas mais claras que podem ter tons claros de rosa, verde ou amarelo. Nestas áreas mais claras ou entre os feixes colágenos vermelhos, podemos observar as células fúngicas como estruturas arredondadas, ovais ou deformadas que se apresentam contornadas por delgada faixa vermelho-escura, externamente à qual pode ser vista outra faixa mais espessa que se apresenta num tom bastante claro de amarelo-esverdeado (Figura 1). $O$ interior do fungo pode ser completamente claro ou apresentar material granuloso de pouca afinidade tintorial. À luz polarizada as células do Paracoccidioides mostram um anel birrefringente, mais espesso e com brilho de cor verde limão, que pode ser acompanhado de um, ou mais raramente, por dois 
anéis delgados e de menor brilho, também esverdeados. $O$ conjunto apresenta-se interrompido em 4 pontos diametralmente opostos, sendo os anéis lisos e homogêneos (Figura 2). As fibras colágenas apresentam-

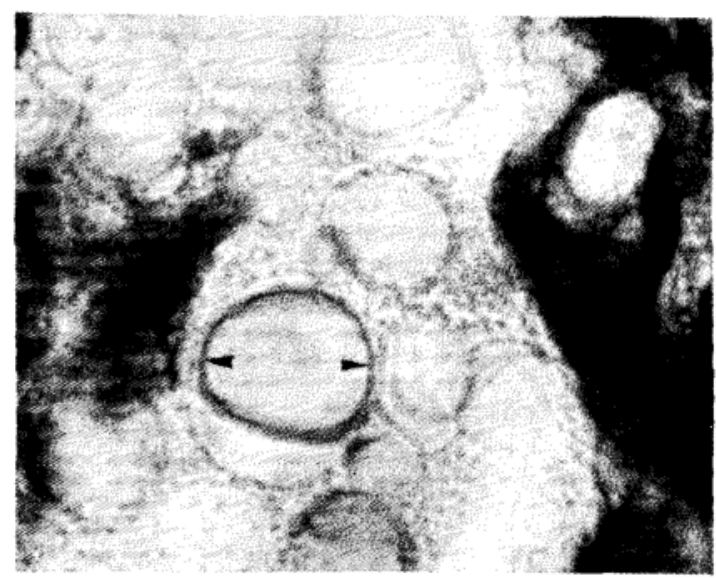

Fig. 1- Corte de linfonodo humano, corado durante 30 minutos pelo picro-sirius após banho de 5 minutos em hidróxido de sódio a $1 g \%$, examinado à luz comum (x2000), mostrando Paracoccidioides brasiliensis que apresentam faixa periférica corada em vermelho que na foto mostra-se mais escura (setas). De cada lado, as áreas mais escuras representam feixes colágenos.

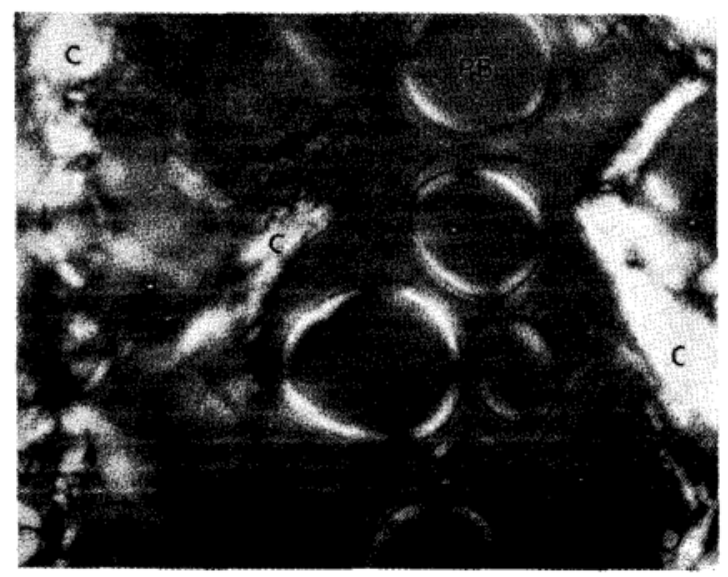

Fig. 2 - Mesmo campo da Fig. 1, visto à luz polarizada. As células do Paracoccidioides brasiliensis $(P B)$ mos tram um anel interno mais brilhante e mais espesso, externamente ao qual pode ser visto outro anel mais delgado e de brilho mais discreto. Os feixes colágenos (C) se apresentam intensamente brilhantes. $x 2000$

se também birrefringentes, com brilho intenso vermelho-amarelado ou mais discreto de cor verde. Estruturas semilunares prateadas podem representar células fúngicas fragmentadas ou colabadas; enquanto estruturas arredondadas apresentando anel periférico e conteúdo, às vezes lembrando cruz de malta, ambos emitindo intensa luz prateada, embora raramente, podem ser vistas em locais onde, à luz comum, identificam-se células fúndicas aparentemente normais. Figuras irregulares e brilhantes que parecem representar partículas contaminantes e pigmento de formol, são facilmente distinguiveis dos grupos de anéis esverdeados que representam as células fúngicas. A comparação de um mesmo campo microscópico à huz comum e à luz polarizada mostra que, apesar de a grande maioria das células fúngicas formarem os anéis birrefringentes descritos, algumas não o fazem, ficando invisíveis à luz polarizada. Os aspectos descritos foram observados tanto nos preparados corados no picro-sirius durante 10 minutos como durante uma hora, parecendo atingir seu máximo entre 30 e 40 minutos de coloração. Quando os cortes são banhados em solução de hidróxido de sódio a $1 \mathrm{~g} \%$, durante dois, até o máximo 20 minutos, antes da coloração pelo picro-sirius, a afinidade do fungo pelo corante e sua birrefringência aumentam sensivelmente, enquanto o colágeno parece não se alterar. Em geral o banho em hidróxido por cinco minutos, seguido de coloração por 30 a 40 minutos, dá bons resultados. Quando fizemos o processo inverso, isto é, quando após coloração pelo picro-sirius imergimos o preparado histológico em solução aquosa de hidróxido de sódio a $0,5 \%$, verificamos sua rápida descoloração macroscopicamente e o exame, à luz polarizada, mostra que enquanto o tecido torna-se escuro conservando o colágeno fraca birrefringência espontânea, as células fúngicas conservam seus brilhantes anéis verdes praticamente inalterados ou com discreta reduçāo do brilho (Figura 3). Em geral os melhores resultados foram obtidos quando as colorações por 30 minutos (ou mais) eram precedidas por banho em hidróxido a $1 \mathrm{~g} \%$ e seguidas de diferenciação por poucos segundos (Figura 3) no hidróxido a $0,5 \%$. Uma mistura de álcool comum $\left(96^{\circ} \mathrm{GL}\right)$ mais solução aquosa de hidróxido de sódio a $1 \mathrm{~g} \%$ na proporção de $4: 1$, produz resultados semethantes aos da solução diferenciadora de hidróxido de sódio a $0,5 \mathrm{~g} \%$. Nos preparados não corados, tratados ou nāo pela solução de hidróxido de sódio, as células fúngicas não são birrefringentes.

Os preparados obtidos dos casos de tuberculose que nos serviram de controle, tanto à luz comum como à luz polarizada, não mostravam nenhuma estrutura que pudesse ser confundida com o Paracoccidioides; as células gigantes e epitelióides coram-se muito discretamente pelo ácido pícrice, rão sendo birrefringentes (Figura 4). As fibras colágenas são delicadas, tortuosas, irregulares e de brilho esverdeado, não formando figuras semelhantes ao fungo.

\section{DISCUSSÃO}

O presente estudo mostra que o picro-sirius, além do colágeno, cora também o Paracoccidioides 


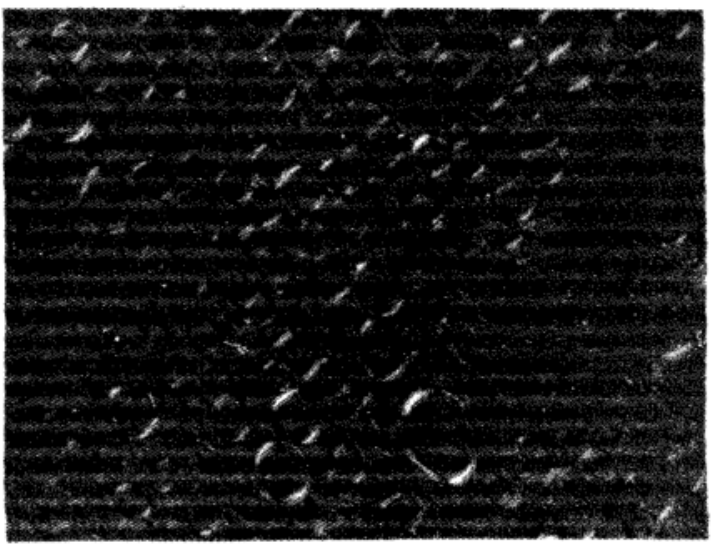

Fig. 3- Aspecto à luz polarizada de preparado histológico de linfonodo corado durante 40 minutos com picrosirius e posteriormente diferenciado em soluçāo de $\mathrm{NaOH}$ a $0,5 \mathrm{~g} \%$. As células do Paracoccidioides conservam birrefringéncia moderada enquanto os feixes colágenos não podem mais ser vistos. $x 500$.

brasiliensis. As células do fungo, quando examinadas ao microscópio de luz comum, apresentam delicada faixa periférica corada em vermelho-escuro que, às vezes, está envolvida por outra faixa clara de aspecto hialino e o seu interior pode apresentar-se vazio ou conter material granuloso. Quando examinado à luz polarizada, em geral, apenas o envoltório mostra-se birrefringente sob a forma de um anel de brilho verde limão que pode ser acompanhado de mais um ou dois anéis externos, mais delgados e menos brilhantes que o primeiro. Os aspectos de birrefringência prateada, às vezes formando figuras em cruz de malta, podem representar artefatos ou um fenômeno cujo significado nos escapa. As faixas vistas com a luz comum e o anel ou anéis brilhantes vistos com a luz polarizada, devem representar componente ou componentes próprios da parede celular do Paracoccidioides. De fato, apesar da semelhança com o colágeno, particularmente o colágeno III que também emite brilho esverdeado, quando corado pelo picro-sirius e examinado à luz polarizada ${ }^{4}$, o tratamento com soluçōes de hidróxido de sódio mostra que o envoltório da célula fúngica $\mathrm{e}$ colágeno tem comportamentos divergentes. $\mathrm{O}$ tratamento dos cortes com hidróxido de sódio antes da coloração aumenta o brilho dos anéis do Paracoccidioides sem alterar de modo evidente o brilho do colágeno; por outro lado, quando os cortes corados pelo picro-sirius são diferenciados em solução de hidróxido de sódio ou de álcool-hidróxido, ocorre rápida descoloração dos colágenos que conservam apenas discreta birrefringência espontânea, enquanto as células do Paracoccidioides conservam seus anéis de brilho esverdeado. Como o fungo não apresenta birrefringência espontânea ou induzida pelo hidróxido de sódio, pode-se admitir que a mesma seja devida à

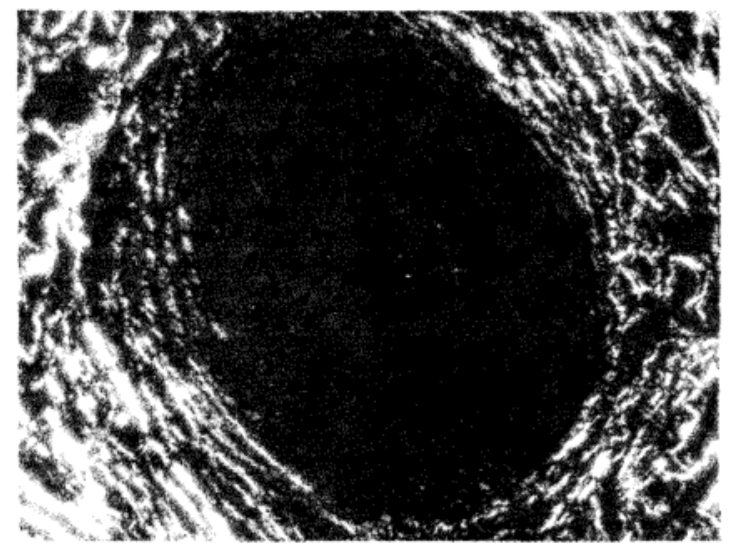

Fig. 4 - Granuloma em caso de tuberculose, corado pelo picro-sirius, visto à luz polarizada - a região das células epitelióides é praticamente sem birrefringència, sendo porém, envolvida por feixes colágenos birrefringentes, sem nenhuma estrutura que se assemelhe aos anéis brilhantes do Paracoccidioides $\times 320$.

fixação do corante às estruturas de sua parede. $O$ Paracoccidioides brasiliensis é um fungo dimórfico com fase leveduriforme nos tecidos ${ }^{5} 78$ cuja parede tem espessura de 150 a $300 \mathrm{~nm}$, apresentando, ao microscópio eletrônico, uma camada interna de baixa eletrodensidade formada por filamentos de quitina e outra externa, mais delgada e mais eletrodensa que a primeira, formada por alfa-glucan ${ }^{78}$. É possivel que os componentes polissacarídeos ou proteinas associadas sejam responsáveis pela afinidade da parede celular do fungo para o vermelho da Síria. Como na paracoccidioidomicose formam-se granulomas e áreas de conjuntivação com alguma semelhança aos da tuberculose, a utilização desta doença como controle nos permitiu verificar se estruturas do granuloma, principalmente o colágeno III que, a julgar pelas descrições existentes (brilho esverdeado, fibras delgadas), poderiam, eventualmente, formar figuras anulares passiveis de serem confundidas com o Paracoccidiodes. Entretanto, nossas observações afastam esta possibilidade, pois as delicadas fibras são tortuosas e irregulares, facilmente distinguiveis dos anéis formados pela parede celular do fungo.

Das variações técnicas descritas, o tratamento prévio com hidróxido de sódio a $1 \mathrm{~g} \%$ seguido de permanência na solução corante por 30 a 40 minutos é a que fornece melhores resultados para identificação, à luz polarizada, do fungo.

\section{SUMMARY}

Picrosirius stain was used for Paracoccidioides brasiliensis in formalin-fixed human tissue. By common light microscopy the fungus shows a red peripheral band and on polarization micros- 
copy, one or more birefringent green rings. Previous immersion in $1 \%$ sodium hidroxide solution enhances the staining and the birefringency of parasitic cells. The differentiation of the stained sections with $0,5 \%$ sodium hydroxide eliminates the birefringency of the collagen more rapidly than that of the paracoccidioides.

Key words: Paracoccidioides brasiliensis. Paracoccidiodomycosis. Picrosirius. Histotechnology. Mycosis.

\section{REFERÊNCIAS BIBLIOGRÁFICAS}

1. Almeida HO, Teixeira VPA, Gobbi H. Utilização do Bouin e do Picro-sirius para identificação do Cryptococcus neoformans nos tecidos humanos. Revista Goiana de Medicina (no prelo).

2. Constantine VS, Mowry RW. The selective staining of human dermal collagen. II - The use of picrosirius red
F3BA with polarization microscopy. Journal of Investigative Dermatology 50:419-424, 1968.

3. Junqueira LCU, Bignolas G, Brentani RR. Picrosirius staining plus polarization microscopy: a especific method for collagen detection in tissue sections. Histochemical Journal 11:447-455, 1979.

4. Junqueira LCU, Cossermelli WS, Brentani RR. Differential staining of collagens type I, II and III by Sirius Red and polarization microscopy. Archivum Histologicum Japonicum 41:267-274, 1978.

5. Minguetti G, Hofmeister RM, Favoro M, Freitas OT. Ultraestrutura do Paracoccidioides brasiliensis II - Na fase leveduriforme. Revista do Instituto de Medicina Tropical de São Paulo 25:161-167, 1983.

6. Montes GS, Junqueira LCU. Biology of collagen. Revue Canadienne de Biologie 41:143-156, 1982.

7. San-Blas G, San-Blas F. Paracoccidioides brasiliensis: cell wall structure and virulence. Mycopathologia 62:77$86,1977$.

8. San-Blas F, San-Blas G. Paracoccidioides brasiliensis. In: Szanislo PL (ed) Fungal dimorphism, Plenun, New York p. 93-120, 1985. 